\title{
¿Bendición del cielo o plaga? El turismo en la España franquista, 1939-1975
}

\author{
Rafael Vallejo Pousada \\ Universidade de Vigo ${ }^{1}$ \\ vallejo@uvigo.es
}

Recibido: 20/04/2015

Aceptado: 07/07/2015

\section{RESUMEN}

En este artículo se plantea como España, de país rezagado en el turismo internacional durante el primer tercio del siglo XX, pasó a convertirse en una potencia turística. Nos preguntamos cómo y por qué se produjo esta transformación; qué papel jugó el turismo de masas en el modelo de desarrollo español entre 1939 y 1975; y abordamos algunas de sus consecuencias socioeconómicas, para preguntarnos si "el turismo fue una bendición del cielo o una plaga" en la España franquista.

Palabras clave: Historia del Turismo, Desarrollo Económico, España.

\section{Blessing from Heaven or Plague? Tourism in Franco's Spain, 1939-1975}

\begin{abstract}
This article explains as Spain, a country still underdeveloped in the field of international tourism during the first third of the twentieth century, went on to become a tourist power. We consider how and why did this transformation happen; What role did mass tourism play on the Spanish model of development between 1939 and 1975; and I address some of their socio-economic consequences, to question if "tourism was a godsend or a plague" in Franco's Spain.
\end{abstract}

Key words: History of Tourism, Economic Development, Spain.

Códigos JEL: N74, L83, O16.

\footnotetext{
1 Este trabajo se beneficia de la financiación recibida a través del Plan Nacional de I+D+i del Ministerio de Economía, que agradecemos (Código: HAR2011-23214).
} 
En la década de 1960 el turismo pasó a ser uno de los "elementos constitutivos" de la vida española, como quería el Conde de Bailén en 1909². España se convirtió durante la dictadura de Franco en uno de los líderes mundiales del turismo de masas vacacional, en una potencia turística. Fue un hecho sorprendente. En el primer tercio del siglo XX el turismo se había desarrollado como actividad económica, pero de forma modesta en términos comparados: España era país regazado en el turismo internacional de aquel período. ¿Cómo y por qué se produjo esta transformación de país turístico rezagado a potencia turística? ¿Qué papel jugó el turismo de masas en el modelo de desarrollo español entre 1939 y 1975? ¿Qué consecuencias socioeconómicas tuvo? ¿Los impactos del turismo en España durante esta etapa histórica permiten catalogarlo como una "bendición" o como "plaga"?

Las respuestas a estas cuestiones son el objeto principal de este trabajo. Las abordaremos a través de tres grandes apartados. El primero está dedicado a los factores que explican la conformación de España en uno de los países líderes del turismo mundial durante la época franquista y los rasgos básicos de su turismo. En el segundo, se presentan las cifras que revelan que el turismo fue una especie de bendición para la economía española de estos años. En el tercero, y en el balance final, se repasan las evidencias del turismo en los años del desarrollismo, derivadas del modelo turístico y de sus impactos, que muestran su otra cara de "plaga".

\section{La conformación de una potencia turística}

Existe una identificación estereotipada entre franquismo y turismo en España. Sin embargo, el turismo moderno como actividad económica emergió durante el primer tercio del siglo XX, plasmado en un turismo diversificado, de interés por el patrimonio cultural y natural y por las prácticas saludables ligadas en origen al paradigma higienista, que se traducen en el turismo balneario y en los baños de ola. El turismo de salud y recreo generó equipamientos visibles en distintos puntos de la geografía española en el último cuarto del siglo XIX, especialmente en las provincias del norte próximas a Francia (San Sebastián, Santander), pero no exclusivamente (Cádiz, Málaga, Alicante, Valencia), y en aquellas que, como Galicia o Cataluña, poseían una buena dotación de aguas termales. ${ }^{3}$

Iniciado el siglo XX se constata una voluntad social y política de incorporar el país a la "industria del turismo", de sumarlo a las corrientes del turismo internacional por sus potencialidades para el progreso material de la nación. Es cierto que existían limitaciones reconocidas, objetivas, en materia de infraestructuras del transporte y sobre todo en la calidad del alojamiento, que desalentaban el viaje a y por España. Pero el turismo entró en estos años en la agenda política (institucionalización de la política turística, desde 1905), vemos aflorar empresas turísticas nacionales privadas en el campo de las agencias, del transporte o del alojamiento, así como la concurrencia de

2 ARCOS, Carlos: "De las grandes ventajas económicas que produciría el desarrollo del turismo en España”, Estudios Turísticos, 27, 1970 [1909], p. 91.

3 ALONSO, Luis; VILAR, Margarita; LINDOSO, Elvira, El agua bienhechora. El turismo termal en España 1700-1936, Alhama de Granada, Observatorio del Termalismo, 2012. 
empresarios extranjeros para proveer servicios a compatriotas en enclaves turísticos (Algeciras, Huelva, La Orotava, Las Palmas....), e incluso surgió el embrión de un sector público de hostelería. Constatamos igualmente el despliegue de planificadas campañas de propaganda turística, el desarrollo de prensa especializada o la celebración de asambleas nacionales y congresos internacionales de turismo en nuestro país. En general, España participó de la multiplicación de la movilidad y las comunicaciones con la difusión de la revolución de los transportes y las tecnologías de la segunda revolución industrial. La revolución de la movilidad, con el tren, los barcos de vapor y los vehículos "turismos", permitió un incipiente desarrollo del turismo con su doble faceta de turismo interior y externo, y de turismo diverso en su motivación y en sus destinos (ciudades, montañas y litoral o espacios termales).

El avance del conjunto de actividades turísticas durante este período no impidió que España mantuviese, ya iniciada la República, una posición rezagada en calidad de nación receptora de turistas forasteros. El número de estos y su aporte de divisas estaban muy lejos de los que recibían Italia, Alemania, Suiza, Austria o Francia. Más aún, la Guerra Civil y la II Guerra Mundial truncaron los avances logrados hasta entonces en el proceso expansivo del turismo español, tanto interior como exterior. Hasta 1949, en que se recibieron casi 284 mil turistas extranjeros, no se superaron las entradas máximas de 1930 (278 mil turistas).

En 1950, España poseía una más que modesta cuota en el mercado turístico mundial: un 1,8 por 100 de los turistas totales y un 0,8 por 100 del ingreso por turismo internacional. En 1960, tras el Plan de Estabilización y la devaluación de la peseta respecto al dólar (de 42 a 60 pesetas), las cosas habían cambiado sustancialmente: España recibía el 6,2 por 100 del turismo mundial y participaba en los ingresos turísticos con una cuota del 4,3 por $100^{5}$. El boom turístico español no había hecho más que empezar. En 1973 la participación española en el turismo mundial alcanzó las mayores cuotas de todo el siglo XX: un 15,9 por 100 de los turistas y un 10,6 por 100 de los ingresos.

En 1950 España recibió 0,43 millones de turistas, en 1955 1,38 millones (el 4,8 por 100 de la población española), en 1959 2,86 millones y en 1960, 4,3 millones (un 14,3 por 100 de la población), que más que se habían duplicado en 1965, con 11,1 millones (el 34,5 por 100 de la población), en tanto que en 1973 y 1975 llegaron 31,6 y 27,4 millones de turistas (los extranjeros que entraron en España provistos de pasaporte, no excursionistas', equivalentes al 90,5 y 77 por 100 de los habitantes del país, respectivamente (cuadro 1). Las medidas del Plan de Estabilización de 1959 fueron influyentes en esta progresión. El aumento el tipo de cambio de 1959 hasta las 60 pesetas-dólar (una devaluación del 42 por 100) equivalió a levantar la barrera que limitaba la ya entonces significativa corriente turística hacia España, al reducir sustancialmente el coste de las vacaciones. La corriente turística de los años cincuen-

${ }^{4}$ CIRER, Joan Carles, "Spain's new coastal destinations. 1883-1936: The mainstay of the development of tourism before the Second World War", Annals of Tourism Research, 45, 2014, pp. 20-21.

5 Estas cifras en VALLEJO, Rafael: De país turístico rezagado a potencia turística. El turismo en la España de Franco, Documento de Trabajo, DT-AEHE, Núm. 1408, 2014; y "Turismo y desarrollo económico en España durante el franquismo, 1939-1975", Revista de la Historia de la Economía y de la Empresa, 7, 2013, p. 445 
ta se convirtió, desde 1960, en riada. El turismo de masas de la década de 1950 se volvió, en el territorio español, un turismo masivo. Esas masas invadieron España de forma pacífica pero explosiva. En la fase desarrollista de la dictadura franquista (1959-1975), el país quedó convertido en uno de los líderes del turismo mundial.

\begin{tabular}{|l|c|c|c|c|c|c|c|c|c|c|c|}
\hline & $\mathbf{1 9 0 1}$ & $\mathbf{1 9 3 0}$ & $\mathbf{1 9 4 0}$ & $\mathbf{1 9 5 0}$ & $\mathbf{1 9 5 5}$ & $\mathbf{1 9 5 7}$ & $\mathbf{1 9 5 9}$ & $\mathbf{1 9 6 0}$ & $\mathbf{1 9 6 5}$ & $\mathbf{1 9 7 0}$ & $\mathbf{1 9 7 5}$ \\
\hline $\begin{array}{l}\text { Población } \\
\text { española } \\
\text { (millones) }\end{array}$ & 18,66 & 23,44 & 25,76 & 27,87 & 29,06 & 29,55 & 30,05 & 30,30 & 32,08 & 33,88 & 35,69 \\
\hline $\begin{array}{l}\text { Turistas } \\
\text { extranjeros } \\
\text { (millones) }\end{array}$ & 0,12 & 0,28 & 0,02 & 0,46 & 1,38 & 2,02 & 2,86 & 4,33 & 11,08 & 21,27 & 27,36 \\
\hline $\begin{array}{l}\text { \% Turistas/ } \\
\text { Población }\end{array}$ & 0,6 & 1,2 & 0,1 & 1,6 & 4,8 & 6,8 & 9,5 & 14,3 & 34,5 & 62,8 & 76,7 \\
\hline
\end{tabular}

Cuadro 1. Turistas extranjeros y población española, 1901-1975.

Fuente: VALLEJO, Rafael: “Turismo y desarrollo...", 2013.

Esta multiplicación del turismo receptivo en apenas dos décadas acuñó los términos de "boom" y "milagro" turístico español. Estos conceptos no se aplicaron sólo en España, pues el "great tourist boom" de la postguerra que tiene como principal motivación el sol y la playa fue un fenómeno muy mediterráneo ${ }^{6}$. En Italia, Portugal o Grecia se observa esta explosión turística, si bien en España fue relativamente más importante. En 1970, el saldo turístico español era el mayor del mundo en volumen absoluto y por habitante 7 , en tanto que por ingresos totales el país ocupaba el primer lugar en Europa, por encima de destinos tradicionales consolidados como Italia y Francia, y el segundo en el mundo tras los Estados Unidos.

¿Cuáles son las claves de éxito turístico español?, ¿por qué entre 1959 y 1975 España consolidó como destino preferido del turismo masivo veraniego movido por las playas, el sol o, en ciertos ámbitos, la diversión nocturna? El vicepresidente del Gobierno, Luis Carrero Blanco, calificó a ese turismo, en 1969, de turismo "de alpargata" 8 , poniendo de relieve su relativamente bajo poder adquisitivo. La competitividad turística española no se sustentaba sólo en los bajos precios (de los salarios, del suelo, del alojamiento,...), pues la riqueza de su patrimonio histórico y natural, su exotismo, la novedad relativa frente a Italia o Francia o la reconocida hospitalidad de los españoles fueron factores relevantes. No obstante, los precios explican en buena medida el éxito del destino España ${ }^{9}$. Al igual que lo hace una demanda turística en

\footnotetext{
6 Para otros países mediterráneos véanse varias contribuciones en MANERA, Carles, SEGRETO, Luciano y POHL, Manfred (eds.): Europe at the Seaside, New York, Berghalm Books, 2009.

7 OCDE, Tourisme internationale et politique du tourisme dans les pays de l'OCDE, Paris, 1972, p. 9.

8 Carrero Blanco, "Consideraciones sobre la conveniencia de proceder a un reajuste ministerial" (15-101969), Archivo General de la Universidad de Navarra, Fondo Carrero Blanco, Caja 049/001/49, f. 14.

9 GABINETE DE ESTUDIOS ECONÓMICOS, "Ensayo sobre valoraciones de las inversiones turísticas en los distintos sectores económicos españoles", Estudios Turísticos, 28, 1970, pp. 18-19; y, "El crecimiento de los precios hoteleros en España", Estudios Turísticos, 35, 1972, p. 5.
} 
crecimiento, apoyada en una modelo laboral con vacaciones retribuidas y empleos estables para la clase media y los trabajadores de la Europa del norte. Tal éxito no sería posible, en todo caso, sin la revolución de la movilidad internacional con la popularización del coche y sobre todo del viaje en avión con los vuelos chárter ${ }^{10}$. La construcción de un sistema de vacaciones organizadas industrialmente en torno al transporte aéreo hizo que la Europa mediterránea se consolidara como la más importante periferia del placer, europea y global. Así, los precios baratos, la longitud de costa y la proximidad de la Europa industrializada (acentuada por la rapidez del transporte aéreo) fueron claves del éxito turístico español. Por otra parte, en ese turismo organizado en torno al viaje en avión, el papel de los turoperadores turísticos del norte de Europa fue muy importante en el caso español. Y lo fue igualmente la respuesta empresarial española, muy dinámica ya en la década de los cincuenta, a la concurrencia de los turistas.

La crisis del petróleo iniciada a finales de 1973 pareció poner en cuestión ese modelo turístico. La participación española en el mercado turístico mundial descendió desde 1974 de forma significativa, en turistas y en ingresos, pero sólo coyunturalmente. España logró mantener, en el último cuarto del siglo XX, una posición de liderazgo como país turístico. Como tal, presentaba los siguientes rasgos. El primero es que ninguna de las economías de los otros países líderes turísticos mundiales tendrá una dependencia tan importante del turismo como la española. La segunda singularidad respecto a los demás líderes turísticos fue la relativamente elevada aportación de los no residentes a los ingresos turísticos totales, así como la poca salida al extranjero de turistas españoles. Esto último origina una balanza turística comparativamente más favorable en el caso español.

Ahora bien, la proyección internacional del mercado turístico español no ha de llevarnos a identificar al español con un turismo exclusivamente receptivo. La incorporación progresiva de los españoles a las actividades turísticas tiene lugar ya desde los primeros años del siglo XX, cuando los viajes y el veraneo se extendían entre la clase media; de hecho, este turismo interior era más importante que el exterior ${ }^{11}$. Tras la II Guerra Mundial, la riada de turismo extranjero -y sus divisas- minimizará la importancia del turismo nacional. Pero la entidad de éste fue en aumento, acompañando al crecimiento de la renta per cápita de los españoles desde los primeros años 1950; el gasto turístico es función de la renta y España en esto no fue una excepción, como prueba la creciente participación del consumo interno en el consumo total de servicios turísticos. ${ }^{12}$ En los años del franquismo, los españoles participaron cada vez más de la salida vacacional veraniega, que convirtió el "veraneo" en un fenómeno sociológico. Veraneo no es siempre equivalente a turismo (la salida vacacional se hacía muchas veces a la casa del pueblo, sin consumo de oferta reglada de alojamientos

\footnotetext{
10 FORSYTH, Peter: “Aviation and tourism”, en Larry DWYER y FORSYHT (eds), International handbook on the Economics of tourism, Cheltenham, Edward Publishing, 2006, pp. 224-226 y 229.

11 PELleJERO, Carmelo: “Antecedentes..”, en C. PELLEJERO (dir.), Historia Económica del Turismo, Madrid, Civitas, 1999, p. 69, MORENO, Ana: Historia ..., pp. 21-132.

12 Cifras y bibliografía al respecto en VALLEJO, Rafael: (2013 y 2014).
} 
turísticos), pero marcó su punto de partida, de tránsito de la vacación al turismo. ${ }^{13}$ Coger las vacaciones conformará un particular turismo doméstico, una especie de signo de distinción social, sustentado en el coche utilitario, el trabajo estable en la ciudad y las vacaciones pagadas. Se estaban poniendo las bases de la "sociedad de turistas" de la que actualmente participamos.

Por tanto, el turismo español durante el franquismo ofrece dos vertientes principales: el turismo de los residentes en el interior y el turismo receptivo. (Una tercera, la del turismo emisor es menor, aunque en la década de los setenta -1978-1979- ya es bien perceptible y motivo de preocupación de las autoridades por su drenaje de divisas). En consecuencia, constituye un fenómeno económico decisivo en el modelo de desarrollo español desde los años cincuenta por su notable contribución al equilibrio de las cuentas exteriores y a la financiación del crecimiento económico y porque la demanda turística de bienes y servicios constituyó una parte nada despreciable de la demanda interior, con efectos sobre el empleo y el conjunto de actividades que conforman la industria del turismo, convertida así en una fuente generadora de renta.

Ahora bien, el turismo no sólo tuvo efectos económicos, en la contabilidad nacional. El hecho de que los arenales de algunas de las provincias mediterráneas y de las islas Baleares y Canarias se convirtieran en uno de los epicentros mundiales del turismo masivo de sol y playa nos sitúa ante un fenómeno demográfico y social de envergadura. El turismo de sol y playa, concentrado en unas cuantas semanas al año, es consumidor de territorio, de espacios naturales y urbanos preexistentes. Por tanto, además de importantes efectos económicos, tuvo relevantes impactos medioambientales, ya perceptibles y registrados en el caso español en informes oficiales de los primeros años sesenta con el inicio del boom turístico, pero no suficientemente contabilizados y menos estudiados que los efectos económicos inmediatos. En los estudios del turismo caben dos miradas, una mirada "de advertencia", crítica, que pone el acento en los efectos o externalidades negativas y una mirada "de defensa del turismo", que subraya sus aportaciones económicas e incluso sus aportes a la conservación del patrimonio natural y cultural, allí donde se producen. ${ }^{14}$ La historia del turismo español también participa de estas dos perspectivas, con un predominio claro de la segunda de las aquí referidas. De ahí que no se haya planteado abiertamente el dilema de si el turismo fue, en la era de Franco, una bendición por sus efectos macroeconómicos o una plaga, teniendo en cuenta sus efectos medioambientales, el modelo de negocio en que se fundamentó y el modelo de desarrollo que indujo. Este dilema lo recogió en 1975 el informe El resurgir económico de España ${ }^{15}$. Aquí lo retomamos.

13 CALLEJO, Javier, "Del veraneo al nomadismo", Claves de razón práctica, 235, 2014, pp. 17-25, se refiere, por ello, a la "generación de salida".

14 Estudios englobables en las denominadas "plataforma de advertencia" y "plataforma de defensa" por RUBIO, Ángeles: “Turismo experiencial”, Claves de razón práctica, 235, 2014, pp. 27-35.

15 STILLMAN, Edmund (dir.), Informe del Hudson Institute Europe. El resurgir económico de España, Madrid, Instituto de Estudios de Planificación, 1975. 


\section{El turismo y el desarrollo económico en la España de Franco}

El turismo español del franquismo se asimila al boom turístico de los años sesenta. Esa identificación hay que matizarla cuando atendemos a sus contribuciones a la economía española, como elemento compensador de los desequilibrios de la balanza de pagos. La colaboración económica del turismo se retrotrae realmente a finales de los años cuarenta y sin duda a los cincuenta, Es no obstante en la década de los sesenta cuando, por su volumen, el aporte se agranda sustancialmente. El turismo exterior es un fenómeno masivo que genera cifras desconocidas de divisas y a su lado se desarrolla un turismo interior con aportaciones sustanciales al consumo y a la renta del país. El turismo influye desde el Plan de Estabilización (1959) en el modelo de desarrollo español. Este fue al fin más dependiente del exterior de lo que la ideología, inicialmente nacionalista, de la dictadura de Franco preconizaba, y también más terciarizado de lo que los planificadores del desarrollo previeron iniciada la década de los sesenta.

Las iniciativas turísticas de la década de 1940, privadas y públicas, y el desarrollo del sector turístico, estuvieron condicionadas por las circunstancias políticas: las consecuencias de la guerra civil, la guerra mundial, el ostracismo del régimen de Franco (1945-1946) y la recolocación de España entre las naciones occidentales (1948), así como la orientación de la política económica general del primer franquismo.

De este modo, si en el contractivo sexenio de 1930-1935, España recibió una media anual de 205 mil turistas extranjeros, esta cifra no fue superada hasta 1949, cuando entraron en el país 284 mil forasteros. Entre 1936 y 1949, España participó con particular intensidad de la caída del movimiento internacional de viajeros. El turismo fue un sector menor en la economía española. Sin embargo, a pesar de los recelos morales y políticos que hubo respecto al mismo, algunos sectores del régimen confiaban en él por sus potencialidades económicas. La experiencia del primer tercio del siglo $\mathrm{XX}$ aportaba pruebas en este sentido. Otro tanto hacía la experiencia internacional, aunque tras la devastadora II Guerra Mundial el escenario europeo era poco halagüeño. La revista americana Foreign Affairs afirmaba en 1947 que Europa disponía "tan poco de todo, tan pocos trenes, tranvías, autobuses o automóviles para llevar a la gente a trabajar, que ¡cómo para llevarles de vacaciones!". Pero el turismo era ya un fenómeno sociológico y económico asentado, que formó parte de la agenda política para la reconstrucción europea. Así, se hicieron rápidos esfuerzos para incluirlo en la coordinación multilateral, impulsada por los americanos, para reconstruir y desarrollar Europa, de modo que la recuperación del turismo internacional formó parte, en 1948, de los objetivos de la OEEC (Organización para la Cooperación Económica Europea). Era considerado uno de los "campos de actividad más importantes y uno de los que tendrá resultados a más largo plazo en la balanza de pagos continental". ${ }^{16} \mathrm{En}$ la temporada del verano de 1948 el reflujo del turismo exterior europeo era perceptible. En ese contexto, también se formularon deseos y expectativas sobre el papel que

16 PACK, Sasha D.: "Turismo en la Europa de la postguerra: de la diplomacia esterliniana al consumismo de masas", TST, 24, 2013, pp. 138-166. 
podía jugar el turismo en el caso español, y se prodigó una activa política turística con ese fin, de la mano de Luis Bolín, director general de turismo desde 1940.

En los años cuarenta la aportación del turismo extranjero a la economía española fue muy modesta. En 1949, los ingresos turísticos suponían un 0,38 por 100 del PIB, aportación inferior a la que se registró entre 1931 y 1934 . Ahora bien, pese a esa modestia, el turismo ya manifestó en esta dramática década sus potencialidades económicas, a través de sus aportaciones a la balanza de pagos. Desde 1947 los ingresos turísticos equivalieron a más del 7 por 100 de las exportaciones y de las importaciones, representaron casi la mitad de los ingresos de la balanza de servicios y financiaron entre el 31 y el 54 por 100 del déficit comercial en 1947-1949. Este déficit fue más que compensado por los ingresos turísticos en 1950, cuando el turismo se mostraba como una de las más prometedoras partidas compensatorias de los desequilibrios de las balanzas comercial y por cuenta corriente, desequilibrio este último que se había agudizado desde 1946. En 1949 el turismo estaba muy lejos de ser considerado como un sector crucial en el modelo español de desarrollo económico, pero las cuentas exteriores aportaban argumentos para tenerlo en cuenta. El turismo en la segunda mitad de la década de 1940 se mostró como una exportación nada despreciable, y como tal fue tratada, a través de correcciones del tipo de cambio "preferente" para los turistas entre 1946 y 1948.

Los resultados del turismo a finales de los cuarenta empezaban a confirmar la predicción optimista hecha por el economista Fuentes Irurozqui en 1946, acerca de la buena dotación recursos de España para desarrollar la "industria del turismo" por su potencial como fuente de ingresos al ser un fenómeno internacional que resurgiría "extraordinariamente" tras la II Guerra Mundial. Dicha predicción la corroboró a fines de 1947 Stanley Norman Bliss, director de importantes servicios turísticos de Estados Unidos. "A España le espera un futuro brillante respecto al turismo", afirmó, porque "en los EE.UU. y en todos los países de América y Europa que he recorrido, he observado este fenómeno: que en los turistas se ha despertado un vivo interés por visitar España". ${ }^{17}$

Lo que sucedió en la década de 1950 confirmó este optimismo. El turismo en la década de 1950 se manifestó como "la más valiosa exportación nacional" tal y como sostenía Juan Plaza Prieto en $1953 .{ }^{18}$ Esta valoración del turismo receptivo en España durante los años cincuenta es atinada, teniendo en cuenta su aporte a la Balanza de pagos.

Su evolución durante esta década hay que inscribirla en la reintegración o progresiva rehabilitación internacional de España, apoyada en las muletas de la ayuda norteamericana, el cambio de gobierno de 1951 y una nueva política económica más abierta al exterior y liberalizadora en el interior. La realidad era tozuda y demostraba que la economía española no podía funcionar sin recurrir al mercado externo, y que los corsés interiores, lejos de garantizar la suficiencia autárquica, asfixiaban la economía, generaban corrupción y mercados negros y creaban un malestar social

17 FUENTES IRUROZQUI, Manuel: Sintesis, 1946, pp. 343-344. CORREYERO, Beatriz y CAL, Rosa: Turismo, 2008, p. 426.

18 PLAZA PRIETO, Juan: “Algunos aspectos económicos del turismo”, Arriba, 18-11-1953. 
evidente, aunque fuera silenciado oficialmente. Los citados apuntalamientos externos pusieron en marcha un ciclo de crecimiento económico extraordinario, con tasas del 5,8 por 100 anual en $1950-1955$ y del 2,6 por 100 en 1955-1959, de modo que en 1954 se recuperó el nivel de renta real per cápita de $1935^{19}$, aunque los salarios eran muy bajos y desiguales sectorialmente y entre hombres y mujeres. Hasta 1954 fue un crecimiento relativamente equilibrado, sin tensiones inflacionistas. Pero desde 1955 se combinaron déficit exterior, inflación -de más del 10 por 100 en 1957 y 1958- y desequilibrio presupuestario, que se retroalimentaban. El déficit de la balanza de pagos era galopante. A diferencia de lo que sucederá en la década de 1960, las partidas compensadoras del desequilibrio comercial y por cuenta corriente (turismo, remesas y capital a largo plazo), aunque importantes no fueron suficientes para equilibrar dicha balanza, hasta el punto de que a mediados de 1959 apenas quedaban divisas para pagar las importaciones. Ante la presumible quiebra exterior de la economía, había que ir a un cambio de rumbo sustancial en la política económica.

En la década de 1950 la entrada de turistas extranjeros siguió la línea ascendente iniciada en 1947, al igual que su contribución a la economía española. De 457 mil turistas recibidos en 1950 se pasó en 1959 a 2,8 millones. El turismo extranjero en 1950 aportó un 0,4 por 100 del PIB, en tanto que en 1954 llegó hasta el 1,6 por 100 del PIB, un valor que mejoró ligeramente en 1959, con el 1,7 por 100.

En 1950-1954, los ingresos turísticos representaron el 16 por 100 de las importaciones del país y un 20 por 100 de las exportaciones. Durante este quinquenio, las divisas del turismo exterior permitieron compensar hasta el 73 por 100 del déficit comercial, cobertura muy importante, que supera la de los años 1965-1969 y 1970-1975 (70 y 69 por 100, respectivamente). Iniciados los 50, la del turismo era la principal partida compensadora de la balanza de pagos; esa compensación fue insuficiente para lograr el equilibrio exterior, pero este déficit exterior hubiera sido sustancialmente mayor de haber faltado los ingresos turísticos. Así, Juan Plaza Prieto constataba en 1953 que el turismo se había convertido en un "excelente maná" para la economía española, una fuente de divisas, con un futuro prometedor teniendo en cuenta las tendencias mundiales de este fenómeno de "masas humanas", del que España participaba como mercado receptor. ${ }^{20}$

Entre 1955 y 1958, las estadísticas oficiales registran que mientras el número de turistas crecía, las divisas ingresadas por turismo caían. La causa era que los turistas se aprovisionaban de pesetas fuera de los cauces legales del Instituto Español de Moneda Extranjera (IEME), motivado por el cambio oficial de la peseta (sobrevalorada). Esto lo sabían las autoridades, que observaban temerosas que se reducían hasta límites preocupantes las divisas disponibles y la capacidad de compra en el exterior.

En 1955-1958, las divisas del turismo sólo cubrieron un 27,8 por 100 del déficit comercial (bastante menos en 1945-1949 y en 1950-1954). El gobierno estaba alarmado. La recuperación de los ingresos turísticos fue, por ello, un objetivo prioritario. Era inevitable fijar un cambio realista de la peseta. Un informe de enero de 1959 del

\footnotetext{
19 Cifras basadas en PRADOS, Leandro: El progreso..., 2003, Apéndice K.

20 La importancia del turismo en la balanza de pagos de este período en CATALAN, Jordi: "Sector exterior y crecimiento industrial", 1995, pp. 99-146. MARTÍNEZ, Elena, "Sector exterior y crecimiento en la España autárquica", 2001, pp. 233-234.
} 
ministerio de Hacienda reconocía que los turistas forasteros adquieren "en el extranjero las pesetas que aquí van a gastarse", porque "la diferencia de cambio extranjero al cambio oficial es importante. (...) El pasado verano [1958], hemos asistido al espectáculo de que todos los turistas extranjeros llegaban con pesetas." En consecuencia, había que devaluar la peseta, aumentando el tipo de cambio, porque sin alterar el "cambio de la peseta en el extranjero se reduce el turismo." 21

Costó tomar esta decisión, porque había que ir a un ajuste global de la economía, empezando por fijar un cambio de la peseta realista y siguiendo por la liberalización del comercio y la entrada de capitales. Pero no hubo más remedio. En julio de 1959 las reservas de oro y divisas en el IEME no llegaban ni para pagar un mes de importaciones. El 17 de julio se fijó la nueva paridad de la peseta en 60 pesetas por dólar y el 21 de julio se aprobó el Plan de Ordenación Económica, más conocido como Plan de Estabilización y liberalización. Las autoridades querían que dicha aprobación se produjera antes de que empezara el grueso de las vacaciones veraniegas, para aprovechar el impulso que experimentarían los ingresos de divisas por turismo, como así sucedió. En consecuencia, el turismo tuvo una importancia destacada en la puesta en marcha del Plan de Estabilización, porque en la década de los 50 se había confirmado como la más importante partida estabilizadora en la balanza de pagos, función que sólo la política monetaria exterior le impedía ejercer plenamente. Con la devaluación de 1959 esa función se vio acrecentada de forma automática. La predicción hecha por Enrique Fuentes Quintana en 1954 se cumplía: la del turismo se consolidaba como una de las "cuentas que habrán de ocupar bastantes folios en el [libro] mayor de nuestro progreso material". ${ }^{22}$

Los beneficios macroeconómicos del turismo fueron evidentes tras 1959. Las divisas turísticas constituyeron la principal partida compensadora en la balanza de pagos: en 1960-1975 financiaron por si solas el 71,5 por 100 del déficit comercial; su montante equivalió al 33 por 100 de las importaciones, el 61,5 por 100 de las exportaciones físicas, el 85 por 100 de las exportaciones por servicios y a un 4,5 por 100 del PIB (apéndice). Los efectos sobre el empleo fueron igualmente notables. Según la estimación de Largo Jiménez, entre 1965 y 1973, los empleos directos e indirectos generados por las actividades turísticas de los no residentes y los residentes, oscilaron entre el 9,5 por 100 y el 13,2 por 100 de la población ocupada (cuadro 2). El turismo constituyó, así, uno de los elementos sustanciales del sistema económico español del franquismo desarrollista.

21 Sostenía el citado informe sobre "Convertibilidad exterior de la peseta y estabilidad monetaria”, Madrid, enero de 1959; Archivo General de la Universidad de Navarra, Fondo Navarro, Caja 98 (014/098/014).

22 FUENTES QUINTANA, Enrique, "Notas sobre comercio exterior”, 1954, p. 194. 


\begin{tabular}{|c|c|c|c|c|}
\hline & Turismo/PNB ${ }^{(a)}$ & Turismo/PNB ${ }^{(\mathrm{b})}$ & $\begin{array}{c}\text { Empleo directo } \\
\text { turismo/ } \\
\text { Población ocupada }\end{array}$ & $\begin{array}{l}\text { Empleo indirecto } \\
\text { turismo/ } \\
\text { Población ocupada }\end{array}$ \\
\hline 1965 & 4,5 & 9,8 & 3,9 & 5,6 \\
\hline 1970 & 4,9 & 12,0 & 5,4 & 7,5 \\
\hline 1973 & 5,3 & 12,0 & 6,2 & 7,0 \\
\hline
\end{tabular}

Cuadro 2. Contribución del turismo al PNB y al empleo, 1965-1973 (Porcentajes).

Fuentes: LARGO, José, “El turismo y la economía nacional”, Estudios Turísticos, 45, 1975, pp. 18 y 21 .

Notas: (a) Turismo se refiere a actividad turística más directa (Hostelería y similares).

(b) Turismo se refiere a todos los sectores destinados a satisfacer la demanda turística (producción turística total).

\section{El boom del turismo en 1960-1975: ¿bendición o plaga?}

\subsection{Un modelo económico abierto y desequilibrado con triple dependencia exte- rior, incluida la del turismo receptivo}

El Plan de Estabilización y liberalización de 21 de julio de 1959 marcó un nuevo rumbo para la economía española. Además de medidas de ajuste coyuntural (subida de impuestos, limitación del crédito, devaluación de la peseta), contenía medidas de largo alcance que sentaban las bases para un nuevo modelo de desarrollo. Se suprimían organismos interventores, se liberalizaba el comercio interior y, más importante, se liberalizaba el comercio exterior. Se comprometía igualmente la liberalización de las inversiones extranjeras: el decreto de 27 de julio de 1959 y los decretos de 24 de diciembre de 1959 y 18 de abril de 1963 fijaron las modalidades de inversión, garantizaron la repatriación de beneficios y eliminaron los límites a la participación del capital extranjero en algunos sectores productivos, entre los que en 1963 se encontraba la "construcción, ampliación y explotación de hoteles."

La nueva política económica inaugurada en 1959 era una enmienda a la totalidad de la desarrollada en la década de 1940. En 1959 se admitió hasta sus últimas consecuencias lo evidenciado muchos años antes: era imposible un crecimiento económico sostenido del país sin el aporte exterior de materias primas, bienes de equipo, tecnología o asistencia técnica y, en general, de ahorro foráneo, esto es, sin integrarse plenamente en el sistema capitalista occidental. Era un modelo que apostaba por la industrialización, reconociendo que era imprescindible el concurso de la inversión extranjera, una inversión del capitalismo liderado por Estados Unidos que no vendría a España sino se le garantizaba libertad económica, incluida una cierta flexibilización del mercado laboral.

Franco, siempre camaleónico, proporcionó los argumentos oficiales para justificar el nuevo rumbo y la apuesta industrializadora del régimen. Lo hizo en el mensaje a los españoles de 31 de diciembre de 1959 y en el de 3 de junio de 1961 a las Cortes celebrando el 25 aniversario del Movimiento Nacional. En ellos asimiló "integración" económica a "industrialización" y ésta a la superación de la "preponderan- 
cia agrícola". Según Franco, algunos estados europeos pretendieron durante el siglo $\mathrm{XX}$ "que España fuese una nación exclusivamente agrícola y un mercado propicio a sus manufacturas". Esto, añadía, era "inexplicable hoy ante el crecimiento de la demografía y la necesidad para todos los Estados de una progresiva industrialización." España tenía que apostar por la industria, superando su tradicional papel de suministrador de alimentos, para evitar que se acentuara su "desnivel" con los países industrializados. ${ }^{23}$

El nuevo modelo de desarrollo abierto al exterior conllevaba un mayor volumen de importaciones y éstas, para ser financiadas, exigían un aumento paralelo de las exportaciones. Pero esta condición básica no se dio: las exportaciones crecieron por debajo de las importaciones. El crecimiento español de la década de los sesenta y primeros setenta fue desequilibrado. La industrialización se produjo a costa de un creciente déficit de la balanza de mercancías, como había sucedido en la década de 1950. Ahora bien, a diferencia de lo sucedido en aquella década -y en la de 1940-, durante estos años hubo partidas compensadoras que garantizaron el superávit de la Balanza de pagos básica, esto es, la capacidad para comprar las materias primas y los bienes de capital necesarios para la agricultura y la industria. Esas partidas fueron, por este orden, las divisas del turismo receptivo, las remesas de los emigrantes y las inversiones extranjeras. El déficit comercial, reflejo de una estructura productiva desequilibrada, fue compensado -salvo en 1965 y 1966- por tres tipos de superávit, representativos de una notable y triple dependencia exterior: el elevado superávit de la balanza de servicios (debido al turismo), el superávit de la balanza de transferencias y el de la balanza de capitales a largo plazo. Estamos aquí ante una de las paradojas del régimen franquista: en origen nacionalista económico, se encontró con que su éxito y legitimación por los resultados materiales se produjo acentuando la dependencia exterior de nuestra economía. Otra paradoja fue que apostó por la industrialización y se encontró por el camino con un desarrollo igualmente vigoroso -e inesperado- del sector servicios, impulsado por las actividades turísticas y el comercio (algo más de la mitad del PIB en 1970). Como consecuencia del turismo, España experimentó desde los años sesenta un nivel de terciarización por encima de la media del conjunto de los países desarrollados. ${ }^{24} \mathrm{El}$ modelo español de industrialización tardía coincidiendo con la terciarización intensiva de la postguerra, asociada a la revolución turística propiciada por el turismo de masas, aconseja enfocar su esquema de desarrollo bajo nuevos paradigmas tecno-económicos ${ }^{25}$.

España no fue, en líneas generales, una excepción en el modelo de desarrollo europeo occidental de estos años. El núcleo industrial de Europa actuó como centro de expansión sobre las economías periféricas mediterráneas, a través de fuerzas impul-

23 Francisco FRANCO, Mensaje de fin de año, de 31 de Diciembre de 1959 y "Mensaje a las Cortes" de 3 de junio de 1961.

${ }^{24}$ CUADRADO, Juan Ramón y DEL RÍO, Clemente: Los servicios... 1993, p. 343; BARCIELA, Carlos; LÓPEZ, Ma . Inmaculada; MELGAREJO, Joaquín y MIRANDA, José A.: La España.. 2001, p. 445.

25 MANERA, Carles, GARAU, Jaume y MOLINA, Ramón: The tourism revolution, AEHE, DT-1014, 2010, pp. 5-9. 
soras (spread) y depresoras ${ }^{26}$. En el caso de la economía española predominaron los spread: ingresos por turismo, remesas de emigrantes y entradas de capital (además de las exportaciones). Así, el turismo extranjero se convirtió en la clave del desarrollo económico español. En clave y también en factor de relativa debilidad, porque dependía del consumo exterior (aunque no exclusivamente dado el desarrollo del turismo interior), al igual que del exterior dependían el trabajo proporcionado a los emigrantes por la industria y los servicios en Francia, Alemania o Suiza, y los créditos y las inversiones directas de capital a largo plazo.

Esta dependencia del desarrollo español respecto al turismo de masas receptivo se convirtió, con el paso de los años, en un motivo de preocupación y de crítica. Esa crítica se fundamentó en los estrangulamientos, tensiones intersectoriales y costes medioambientales generados por las actividades turísticas. Esto llevó al debate, a mediados de los años setenta (con la crisis internacional desde 1973), de si el "maná" del turismo era en España "una bendición del cielo o una plaga" 27.

\subsection{El equilibrio de la Balanza de pagos depende de los ingresos por turismo receptivo}

A raíz de haberse fijado el tipo de cambio en 1959 en 60 pesetas-dólar (una devaluación del 42 por 100), las compras de los turistas extranjeros volvieron a los cauces legales; en 1959, los ingresos turísticos cubrieron el 67 por 100 del déficit comercial y en 1961 el 139 por 100 del mismo. De repente pasamos de 2,9 millones de turistas en 1959 a 4,3 millones en 1960, el 14,3 por 100 de la población española. Con aquella avalancha, el turismo de masas de la década de 1950 se convertía, en el territorio español, en un turismo masivo.

Nada más iniciarse la década de 1960, el turismo era "nuestra primerísima exportación". A partir de entonces, "el auge incesante de la corriente turística" que identificaba la revista Información Comercial Española en mayo de 1961 se convirtió en una riada que creció de forma casi espontánea, esto es, más allá de la voluntad de los gobernantes por fomentarla y de la de los empresarios españoles del sector por beneficiarse de ella. La inclinación de los vecinos europeos del norte a gozar de las playas y el de España, el aumento del nivel de vida en toda Europa y la realista paridad oficial de la peseta adoptada en julio de 1959, traducida en unos precios sustancialmente más reducidos que los de los competidores europeos, fueron factores que, unidos a la iniciativa empresarial turística en España, explican en buena medida el renovado auge turístico.

Estas masas de turistas procedían, por este orden, de Francia, Gran Bretaña, Alemania y, cada vez menos, de Estados Unidos. Llegaban pacíficamente en sus coches y, cada vez más, en viajes (todo incluido) organizados por tour operadores apoyados en las compañías aéreas de vuelos chárter, concentrándose geográficamente en 9 provincias (de las 50 que tiene el país) y durante un período breve de tiempo, dando

26 Términos de Gunnar Myrdal (1968), cuyo análisis fue aplicado al caso español por ROMÁN, Manuel: Los límites del crecimiento en España, 1959-1967, Madrid, Ayuso, 1972.

27 STILLMAN Edmund (dir), Informe..., p. 188. 
lugar a impactos notables y de diversa índole, en el paisaje natural y humano e indudablemente en la economía y la sociología del país. En 1965 los 11,1 millones de turistas extranjeros equivalían al 34,3 por 100 de la población autóctona, en tanto que en 1973 (31,6 millones) al 90,5 por 100. En torno a un 40 por 100 de esos turistas se concentraban en los meses de julio y agosto; en estos dos meses, la población flotante del turismo llega a multiplicar por más de diez la población permanente de las localidades turísticas ${ }^{28}$ lo que creó problemas de congestión y diversos estrangulamientos: agua potable, aguas fecales (contaminación por colibacilos y episodios de tifus y gastroenteritis), luz eléctrica, telefonía, basuras, ruido, atascos y problemas de aparcamiento de coches, equipamientos sociales y sanitarios, etc. En consecuencia, la riada tuvo efectos benéficos, pero sus desbordamientos generaron costes sociales y medioambientales, al tiempo que modificaban la estructura económica, de forma muy visible en las provincias afectadas, a veces en conflicto con la agricultura o la industria local, por los usos alternativos y excluyentes del territorio o por la mano de obra $^{29}$.

Los beneficios macroeconómicos del turismo extranjero son evidentes. Las divisas turísticas constituyen la principal partida compensadora de la balanza de pagos: en el período 1960-1975 financian por si solas el 71,5 por 100 del déficit comercial y hubo algún año, como 1965, en que los ingresos turísticos superaron los de las exportaciones. Esto preocupó a las autoridades y a los economistas. La capacidad exportadora de la industria del país no despegaba, pese a los evidentes avances de la industrialización, debido a la débil competitividad internacional de la economía española, a la que la inflación, alta y persistente desde 1962, ayudaba poco. De ahí que se hable del "monocultivo del sol" en los años del estricto "boom turístico" (1960-1964), cuando la corriente turística ofrecía "cifras espectaculares" y un año tras otro volvía "incluso a desbordar las ilusiones de los más optimistas." ${ }^{30}$

Los planificadores del desarrollo padecían al comprobar que sus previsiones para el I Plan de Desarrollo (1964-1967) respecto a la balanza exterior se habían equivocado notablemente, porque el déficit en la balanza de mercancías fue un 18 por 100 superior al previsto y los ingresos por turismo fueron un 26 por 100 mayores que los previstos. ${ }^{31}$ Las cosas mejoraron algo desde 1967, por el mayor dinamismo de las exportaciones, en parte gracias a la devaluación de la peseta de 1967 y a la política de apoyo fiscal y crediticio a las exportaciones industriales, en el contexto del proceso de industrialización acelerada que experimentaba el país, apoyada en parte en el acceso a las innovaciones con la compra tecnología extranjera ${ }^{32}$, de modo que las exportaciones industriales ya superaron ampliamente a la de productos agrarios ${ }^{33}$. Pero

28 Como sucedía en la Costa Brava, PUIG, José: "Evolución de la Costa Brava", ICE, 421, 1968, p. 90. MALUQUER, Jordi: "El turismo, motor fundamental de la economía de Cataluña", Historia Contemporánea, 42, 2011, pp. 347-399.

29 CUADRADO, José Ramón y TORRES, Enrique, “El sector turístico...”, ICE, 533, 1978, pp. 82-105.

30 "El monocultivo del sol", editorial de ICE, 376, 1964, p. 49.

31 VALLEJO, Rafael, “Turismo y desarrollo ....", p. 445.

32 Carreras y Tafunell (2003), pp. 342; López y Valdaliso (2001); Cebrián (2005); Virós (2013). Sobre las políticas de desarrollo industrial, De la Torre y García-Zúñiga (2013).

33 BIESCAS, José Antonio: "Estructura y coyunturas económicas", en BIESCAS TUÑóN: Historia de España, X, Barcelona, Lábor, 1994, p. 84. 
la balanza de pagos siguió dependiendo en buena medida del comportamiento del turismo receptivo y esta dependencia sólo se debilitó en 1974-1975, cuando la crisis económica internacional hizo retroceder el número de turistas y de divisas turísticas. En 1971 y 1972 los ingresos por turismo habían más que compensado el persistente déficit de la balanza comercial.

Este desarrollo económico desequilibrado azuzó a principios de la década de 1970 el debate sobre el modelo de desarrollo español. La alternativa ya no se planteaba como en la década de 1940 entre industria versus agricultura, sino entre industria y capitalización humana frente a turismo, al tiempo que se identificaba la española como una "economía de balneario", con actitudes que iban desde el temor y crítica por esa terciarización turística hasta su defensa, entre el "pesimismo y el optimismo respecto al desarrollo español". ${ }^{34}$ La crisis económica internacional acentuó aquel temor en 1974 y 1975 . Entonces retrocedieron los ingresos por turismo y las remesas, se agudizó el déficit comercial y reapareció, desde 1973, el déficit por cuenta corriente. La crisis afloró los problemas estructurales del sistema económico español, coyunturalmente reflejados en la caída de reservas y el aumento del endeudamiento exterior. En ese escenario murió Franco.

El crecimiento de las cifras turísticas (turistas e ingresos) fue positivo hasta 1973. Hubo ciclos de mayor y menor dinamismo, pero en general se observa una tendencia a la ralentización desde 1965, sobre todo de los ingresos reales, por la importancia de la inflación en este período (cuadro 2). Las tasas de crecimiento más bajas en la llegada de turistas se produjeron en 1965, 1967-1968, 1973 y 1974-1975, bienio que conoció tasas negativas; entremedias, en 1969-1973, se alcanzaron altas tasas, del 12 al 24 por 100 anual. El crecimiento más bajo de los ingresos reales, inferior al 4 por 100 anual, se dio en 1967-1969; incluso en 1968 los ingresos por turismo receptivo retrocedieron un 4,8 por 100 en términos reales. Las dificultades de la economía internacional en 1967-1968 afectaron al movimiento de turistas hacia España y a sus gastos. La devaluación de la peseta en 1967 no tuvo, esta vez, efectos dinamizadores sobre la corriente turística. Influyeron varios factores: un mayor gasto canalizado en origen por los tour operadores extranjeros; una sobreoferta en el alojamiento que empujó los precios a la baja, debido al dominio de mercado de que disponían los mayoristas de los países emisores; y una caída de la calidad (nivel de gasto) del turismo receptivo. En 1971 y 1972 el crecimiento de los ingresos fue asimismo comparativamente bajo, del 6-7 por 100, en contraposición al aumento de turistas, en tanto que en 1974 y 1975 retrocedieron los ingresos reales, un 17 y un 5,4 por 100, respectivamente.

34 II Semana Económica internacional: Problemas económicos actuales, 1972, pp. 319-322 y ROLDÁN, Santiago y GARCÍA DELGADO, José Luis (1973), "Los nuevos mecanismos de equilibrio de la economía española con el exterior”, en VELARDE (dir.), La España de los años 70, 1973, p. 858. 


\begin{tabular}{|r|r|r|r|}
\hline & \multicolumn{1}{|c|}{ Turistas } & \multicolumn{1}{c|}{$\begin{array}{c}\text { Ingresos } \\
\text { (nominales) }\end{array}$} & \multicolumn{2}{c|}{$\begin{array}{c}\text { Ingresos } \\
\text { (reales) }\end{array}$} \\
\hline $1940-1945$ & 15,7 & $-9,8$ & $-17,1$ \\
\hline $1945-1950$ & 63,4 & 79,2 & 57,1 \\
\hline $1950-1955$ & 24,8 & 47,3 & 37,0 \\
\hline $1955-1960$ & 25,6 & 32,1 & 20,8 \\
\hline $1960-1965$ & 20,7 & 29,9 & 22,8 \\
\hline $1965-1970$ & 13,9 & 12,1 & 6,5 \\
\hline $1970-1975$ & 5,2 & 11,3 & $-0,5$ \\
\hline
\end{tabular}

Cuadro 2. Tasas de crecimiento anual de turistas e ingresos por turismo (nominales y reales).

Fuentes: Prados (2003) y Tena (2005). Elaboración propia.

El crecimiento turístico descrito estuvo lejos de ser ordenado. Al lado de los indudables beneficios surgieran efectos negativos, externalidades que afectaron a toda la sociedad y problemas más específicos sectoriales, que incidieron sobre los agentes directamente implicados. Unos son problemas de crecimiento; otros de madurez del destino. Veamos algunos.

\subsection{La demanda y sus intermediarios dominan la oferta: ¿dependencia colonial?}

La ralentización del crecimiento turístico era esperable, porque las tasas de 1961 a 1964 habían sido espectaculares. Esa ralentización también se dio en otros destinos europeos de la época. Lo singular del caso español es que a partir de 1965, la moderación de los ingresos reales fue acompañada de la caída del gasto real medio por turista (gráfico 1) y de una creciente presión de los tour operadores extranjeros sobre los hosteleros españoles.

Los problemas de fondo estaban en la sobreoferta de alojamientos, la especialización en un turismo masivo de relativamente bajo poder adquisitivo con una motivación dominante de sol y playa y por ello altamente estacionalizado, y un turismo muy concentrado en su geografía emisora (Francia, Gran Bretaña y Alemania) y receptora; menos de una decena de provincias acogían la mayor parte del turismo extranjero, que acentuó en este período su orientación mediterránea y sobre todo isleña, de modo que las economías de Baleares y las Canarias ofrecían en 1975 un alto grado de especialización turística, de modo que la participación del PIB turístico en el total de Baleares quintuplicaba la media española y en Canarias la multiplicaba por 2,735. Este turismo accedía cada vez más al país por medio de programas turísticos integrales, ofrecidos por tour operadores de los países emisores, que incluían el alojamiento en complejos turísticos controlados o participados por inversores extranjeros. Se trata, en este caso, de empresas turísticas instaladas en España en las que existen

35 VALLEJO, Rafael: "Economía e historia del turismo español del siglo XX", Historia Contemporánea, 25, 2002, p. 220. URIEL, Ezequiel (dir.), El sector turístico en España, 2001, p. 404; MANERA, Carles, "El creixement de l'economia turística a les Illes Balears", Recerques, 58/59, 2009, pp. 151-192 y MACÍAS. Antonio y PÉREZ, Concepción: "El turismo en la historia económica de Canarias", en C. Barciela, C. Manera, R. Molina y A. di Vittorio (eds.), La evolución..., 2009, pp. 179-231. 
numerosas concentraciones verticales. ${ }^{36}$ Es lo que sucede, por ejemplo, en las islas Canarias a principios de la década de 1970, cuyo litoral estuvo sometido a una intensa colonización por promotoras inmobiliarias alemanas, directamente o a través de testaferros, que ofrecían en Alemania alojamientos "en uno de los últimos paraísos de esta tierra" donde la "Naturaleza está intacta", a tan sólo cuatro horas de vuelo. Esas " $<<$ colonias $>>$ extranjeras" también se observan en la costa levantina, balear y en la Costa del Sol ${ }^{37}$. Aquí, se impusieron la "Rentabilidad y la Plusvalía", al tiempo que llegaban, en el tránsito de los sesenta a los setenta, "los grandes inversores", los "grupos financieros internacionales", paralelamente al "desarrollo de otra industria de locos que avanza a un ritmo más acelerado: la Aeronáutica". ${ }^{38}$

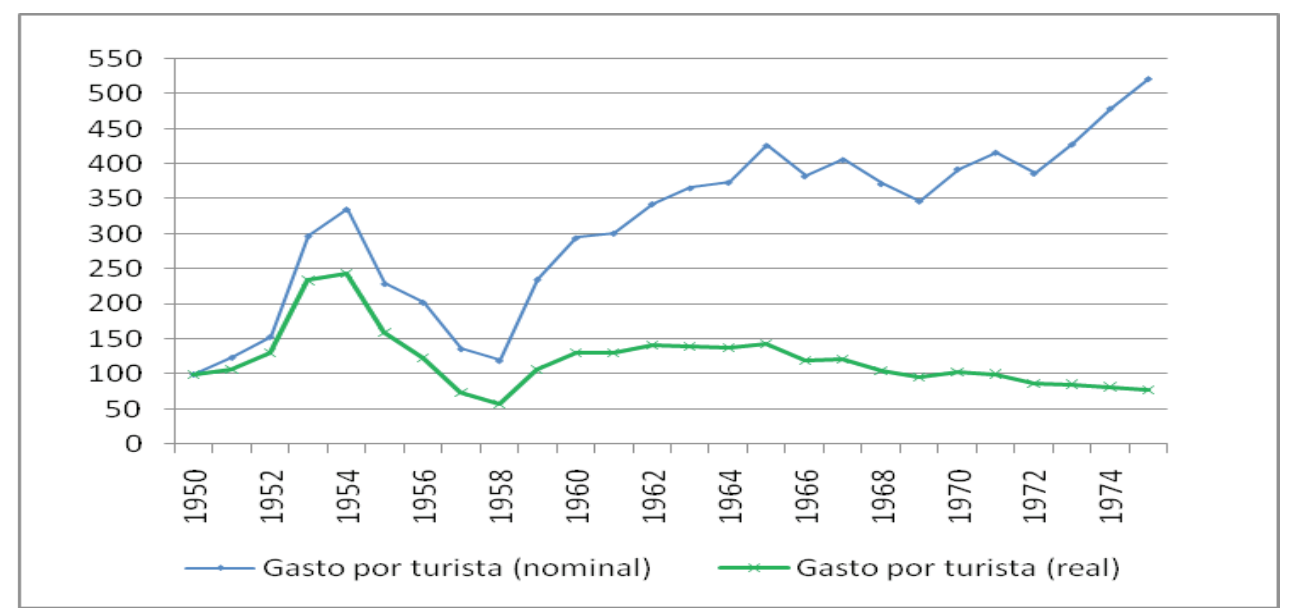

Gráfico 1. Evolución del gasto nominal y real por turista extranjero, 1950-1975 (1950=100). Fuentes: Prados (2003) y Tena (2005). Elaboración propia.

El control se extendió sobre los hosteleros españoles, a través de un proceso de dependencia cuyo origen estaba en la financiación para la construcción de instalaciones, recibida de las agencias extranjeras, y en las contraprestaciones otorgadas en forma de oferta garantizada, preferente y a precios estables y bajos. Estos mecanismos de dependencia, no generalizados en todos los destinos, se agudizaron en los años de demanda débil y sobreoferta, como constatamos en 1965, en 1967-1969 y en los primeros setenta. La escasez de financiación pública o el retraimiento de la banca privada respecto al negocio turístico son parte de la explicación de este modelo de financiación, desarrollado al calor de las expectativas a corto plazo. ${ }^{39}$ La naturaleza del

36 CALS, Joan: Turismo y política turística en España, Barcelona, Ariel, 1974, pp. 23 y 182, estimó en un 25 por 100 la participación del capital extranjero en el sector propiamente turístico.

37 GAVIRIA, Mario: España a Go-Go, Madrid, Turner, 1974, p. 324 y HUETZ DE LEMPS, Alain: L'économie de l'Espagne, Paris, Masson, 1988, p. 251.

38 PALOMINO, Ángel, El milagro turístico, Barcelona, Plaza \& Janés, 1972, 206-240.

39 FUSTER, Juan, “Turismo”, en Juan Velarde (dir.), La España de los años 70, 1973, pp. 813-816; CALS, Joan: Turismo..., pp. 155-165 y 182-186; VILA, Jorge, “Aspectos socioeconómicos del turismo...”, ICE, 533, 1978, pp. 44-51. 
producto (controlado por los intermediarios de la demanda final) y las relativamente bajas tasas de ocupación hotelera, debido a la concentración veraniega, no dejaban excesiva margen de actuación a la industria turística española (hostelería y agencias de viajes). Ésta se comportó respecto a una parte significativa del turismo extranjero como precio-aceptante debido al poder oligopolístico de los tour operadores; dicha subordinación recortó sus tasas de beneficios. ${ }^{40}$ Además, el control de las agencias extranjeras disminuyó las divisas ingresadas por turismo debido a una proporción significativa del gasto de los turistas extranjeros se quedó en los países emisores.

La combinación del control de la oferta por los potentes tour operadores extranjeros con la importante inversión extranjera en el sector mobiliario del alojamiento turístico y vacacional, lleven a hablar, a fines de los sesenta y primeros setenta, de dependencia y colonialismo turístico ${ }^{41}$. Aunque en esto no hay unanimidad.

\subsection{La oferta extrahotelera no reglada supera a la oferta de alojamientos reglada}

Durante estos años, la oferta turística no se limitó a la hostelería "clásica", sino que se desarrollaron nuevas fórmulas de alojamiento, entre las que destacan los bloques de apartamentos, ya en los primeros años sesenta. Fue tal la fiebre constructora de éstos que sólo en la costa de Málaga, entre Nerja y Estepona, se levantaron más 4.000 apartamentos en 1962-1963, con capacidad para unas 10.000 camas, una provincia que en 1964 ofrecía sólo 13.056 plazas de hostelería; en Baleares, por su parte, la Delegación provincial de Información y Turismo evaluaba en 13.000 las camas de los apartamentos en 1963, frente a las 43.015 plazas de la hostelería. ${ }^{42}$ Ya entonces, la de los apartamentos se convirtió en la modalidad de construcción turística más apetecida por los inversores. Este tipo de alojamientos, que se adaptaba bien al turismo familiar extranjero y nacional, inicialmente careció de reglamentación oficial y no estuvo sujeto a los controles que ejercían las autoridades turísticas sobre hoteles y pensiones, permaneciendo en la extralegalidad.

La industria del alojamiento turístico tuvo, fuera de la hostelería, una dimensión altamente especulativa en la construcción y la reventa: los apartamentos se vendían, con pingües beneficios, tres o cuatro veces antes de finalizar su construcción, afirmaba en 1963 Jorge Vila Fradera, Delegado provincial de Información y Turismo en Barcelona. En 1962 el Ministerio de Información y Turismo reconocía que "la especulación sobre terreno y otras propiedades ha forzado y está forzando, cada día más, una construcción excesiva de edificación que supone, en ocasiones una esterilización turística a largo plazo". ${ }^{43}$ Este modelo de las "torres" de apartamentos se extendió por parajes litorales vírgenes, contribuyendo a la destrucción paisajística y medioambiental. Expresión del desorden de este desarrollo es que hasta el 17 de enero de 1967 no

40 Bajas "como norma” a principios de la década de 1970, según CALS, Joan: Turismo..., 1974, p. 163.

41 GAVIRIA, Mario, España..., 1974.

42 SÁNCHEZ, Ceferino: "Málaga", ICE, 363, p. 152, para los apartamentos; ESTEVE y FUENTES: Economía, historia e instituciones del turismo..., 2000, p. 204, para las plazas de hostelería. Baleares en VILA, Jorge: “Auge y problemática de la industria turística balear”, ICE, 363, 1963, pp. 134-135.

43 Ministerio de Información y Turismo: Algunas ideas para la elaboración de las Bases de un Plan Nacional de Turismo, 1962, p. 6. 
se reglamentaron los apartamentos, bungalows y alojamientos similares, y que hasta 1970 el Ministerio de Información y Turismo careció de un censo sobre los apartamentos. Este censo permitió identificar los que estaban fuera de la oferta turística y los destinados a actividades turísticas y, dentro de éstos, los inscritos en el Registro de Empresas y Actividades Turísticas y los no inscritos (ilegales). La capacidad de estos últimos se cifraba en 978 mil plazas, que equivalían al 41 por 100 de la capacidad total de los establecimientos hoteleros y extrahoteleros censados en 1970 por el Ministerio. ${ }^{44}$

El problema de esos apartamentos incontrolados no se quedó sólo en los impuestos que año tras años escaparon al fisco y en su repercusión permanente sobre los paisajes, sino que trascendió a la cultura empresarial. La industria de la construcción turística asentó, con la complicidad de las autoridades, un espíritu empresarial del todo vale, corruptor y desmoralizador. Durante la Transición, a partir de 1975, se creyó que la democracia extinguiría el mal, identificado como producto de un régimen dictatorial y corrompido. ${ }^{45}$ Pero no fue así, la cultura inmobiliaria especulativa, depredadora, quedó enquistada y hoy lamentablemente sigue vigente, enriqueciendo a unos pocos en contra del bienestar colectivo y de la riqueza natural del país, con efectos acumulativos e irreversibles. En esto existe una contradicción entre los beneficios (especulativos) a corto plazo y las externalidades (negativas) a medio y largo plazo. Es una de las pesadas herencias del boom turístico español, frente al que las autoridades franquistas no hicieron prácticamente nada eficaz, impotentes o más bien partícipes del desaguisado. ${ }^{46}$

\subsection{Una política turística exuberante y desbordada}

Entre 1960 y 1975 hubo seis ministros de Información y Turismo: Arias Salgado (1952-1962); Manuel Fraga (1962-1969), un personaje central en la política turística del desarrollismo, Sánchez Bella (1969-1973), Fernando Liñán (1973-1974), Pío Cabanillas (1974) y León Herrera (1975). La inestabilidad en el cargo, a partir de 1973, reflejaba las dificultades de la época y del régimen.

Las líneas principales del período 1960-1962 estuvieron marcadas por la apertura y la liberalización que siguió a la estabilización de 1959, concretadas en la eliminación y simplificación de trámites de visados y aduanas, la liberación de los controles de divisas y las facilidades para la inversión extranjera. En medios económicos y especializados se explicitó la preocupación por las insuficiencias de la política turística en su aspecto económico, empezando por la carencia de los datos estadísticos necesarios para fundamentarla. Jorge Vila Fradera o Felix Varela lo atribuían a la resistencia,

44 Ver III Plan de Desarrollo Económico y Social. Turismo, 1972, pp. 28-36.

45 Por ejemplo, SAVAL, Vicente: "España y su turismo de masas", ICE, 34, 1978, p. 39.

46 Sobre el "tremendo impacto ambiental en los municipios del Mediterráneo español" de la "fórmula de turismo residencial de rápido crecimiento no planificado", ALEDO, MAZÓN, MANTECÓN, Alejandro: "La insostenibilidad del turismo residencial”, en Antropología y turismo, México, 2007, pp. 185-208. 
"en círculos relevantes, intelectual y políticamente", a reconocer el papel económico ya desempeñado por el turismo. ${ }^{47}$

Este desajuste entre una realidad turística desbordante y la política turística es el que afrontó Fraga al frente del MIT desde julio de 1962. Éste recogió muchas de las recomendaciones efectuadas respecto al turismo por el Banco Mundial en su Informe de 1962 sobre la economía española, como la de otorgarle más peso institucional. Fraga asumió la idea de potenciar el turismo como factor de desarrollo económico sin olvidar su proyección y "alta rentabilidad política", que empleó con profusión dentro y fuera de las fronteras españolas.$^{48} \mathrm{Su}$ política, pródiga, tuvo distintos planos. Uno de ellos fue el de la reforma institucional -creación de un Subsecretaría para el turismo, ${ }^{49}$ Instituto de Estudios Turísticos (1962), Ley de Competencias en Materia Turística (1963), reorganización de la Comisión Interministerial de Turismo (1964), Ley de Centros y Zonas de Interés Turístico (1963). Otro plano, el de la política de ordenación y cualificación de la oferta, fue amplio, en consonancia con el crecimiento del tejido empresarial: Agencias de Viajes, Escuela Oficial de Turismo (1963) y enseñanzas turísticas, Empresas y Actividades Turísticas Privadas, establecimientos turísticos (hoteles, restaurantes, apartamentos y otra oferta extrahotelera), etc. En esta política de oferta hay que incluir la política de precios, que tendieron a liberalizarse, así como el Registro de denominaciones Geoturísticas, las Asambleas de Turismo y la continuación del Crédito Hotelero (luego Crédito Turístico); también se aprobaron el Seguro Turístico y el Seguro Obligatorio de Viajeros. En cuanto a la oferta pública, se creó en 1963 la Empresa Nacional de Turismo (Entursa), integrada en el INI, dedicada sobre todo a Hoteles de gran calidad ${ }^{50}$, y fue adquirida Marsans (1964), para actuar en el ámbito de las grandes agencias de viajes. Los 37 establecimientos turísticos del Ministerio con sus 1.877 plazas de 1962 pasaron a 78 y 4.317 plazas en 1969 y 80 y 4.376 , respectivamente, en 1975. Asimismo se promovieron programas sectoriales para diversificar y desestacionalizar el turismo y ambiciosas acciones de promoción y propaganda, faceta propagandística ejecutada con gran habilidad por el equipo de Fraga.

¿Cuánto de los resultados dependió de esa política turística? Valorar con rigor las políticas siempre es difícil, sobre todo cuando, como en este caso, ofrecen objetivos tan amplios e instrumentos tan diversos (regulación, crédito, fiscalidad, etc.). Pero caben algunas conjeturas. En primer lugar, estamos ante una política que nadó a favor de una corriente que era obligado encauzar; cualquiera en el sitio de Fraga tendría que haber tomado múltiples decisiones, como él hizo. En segundo lugar, estamos ante un turismo masivo europeo en el que la voluntad de viajar depende de factores dados (renta de los extranjeros, proximidad geográfica, gusto por el sol y la playa, régimen

\footnotetext{
47 "El turismo", ICE, 1961, 333, p. 73; VARELA, Félix: "Industria turística nacional” y VILA, Jorge "Comentario a la ponencia", ambos en El desarrollo económico de España, 1963, pp. 285-300 y 303-310.

48 FRAGA, Manuel: "El Turismo en España”, Estudios Turísticos, 1, 1964, p. 5; PACK, Sasha D.: La invasión pacífica. Los turistas y la España de Franco, Barcelona, 1999, p. 171 y ss.

49 Decreto de 8-91962, BOE, 221, p. 13.052.

50 PELLEJERO, Carmelo: El Instituto Nacional de Industria en el Sector Turístico. Atesa (1949-1981) y Entursa (1963-1986), Málaga, 2000, p. 136 y ss. VELASCO, María: La política turística. Gobierno y Administración Turística en España (1952-2004), Valencia, 2004, pp. 140-170.
} 
vacacional, etc.) y poco de las decisiones políticas españolas. Lo expresó bien Juan Fuster: "nuestro turismo es un hecho natural, escasamente forzado por la política turística." ${ }^{51}$ Prueba de ello es que pese a los diagnósticos y a los propósitos, ni las primeras iniciativas planificadoras del Ministerio, ni después los sucesivos Planes de Desarrollo del Gobierno, que otorgaron una indudable importancia al turismo, fueron capaces de corregir sus rasgos y problemas estructurales. Por el lado de la demanda destacan la triple concentración (veraniega, de origen y de destinos); la descrita prevalencia de los tour operadores foráneos; $\mathrm{y}$, la cierta colonización de las costas turísticas por inversores extranjeros, incluso estimulada vía incentivos crediticios y fiscales. Por el lado de la oferta encontramos insuficiencias en la cualificación profesional de empresarios y trabajadores del sector, pese a los avances registrados; la saturación o los estrangulamientos locales, como consecuencia de unos ayuntamientos infradotados para multiplicar los servicios públicos al compás de la demanda, porque no se aprobó ninguna reforma de la Hacienda municipal que lo hiciera posible, ya que la de 1962 fue muy insuficiente y el Proyecto de Ley de Bases de Régimen Local de 1971, que preveía un régimen especial para los municipios turísticos, no pasó de tal, al ser retirado de las Cortes en $1973^{52}$; también constatamos el deterioro paisajístico y medioambiental pese a la Ley de Centros y Zonas de Interés Turístico, de escasa efectividad a este respecto.

Otro tanto pasó en el conocimiento económico o sociológico del fenómeno turístico. Las realizaciones del Instituto de Estudios Turísticos (IET) fueron importantes -ahí está la revista de Estudios Turísticos o las monografías del IET para demostrarlo-, pero las estadísticas continuaron ofreciendo problemas en la cuantificación de los estrictos turistas, la contabilización de los ingresos por divisas también ofrece dudas y los censos que permitieran conocer toda la oferta de alojamientos no se hicieron hasta 1970. A su vez, los estudios de mercado realizados en base a encuestas estuvieron muy por debajo de la importancia del turismo, aun cuando el 6 de agosto de 1962 el Consejo de Ministros encargaba al Instituto Nacional de Estadística (INE) la elaboración de un Plan de Estadísticas de Turismo. La Encuesta sobre el turismo receptivo en España, de agosto de 1964, no tuvo continuidad hasta 1970. ${ }^{53}$ En 1968 tampoco se conocía el número de pernoctaciones originadas por los extranjeros, que es la medida más precisa de la demanda real turística ${ }^{54}$. Los datos sobre pernoctaciones que hoy poseemos arrancan de ese año.

La política turística pletórica de Fraga sucumbió al triunfalismo de los números, al aumento de las cifras respecto al año anterior. Frente a ese éxito cuantitativo, los problemas cualitativos detectados, no resueltos por la administración Fraga, persistieron e incluso se agravaron. Como tales, pasaron a la agenda de su sucesor en el

51 FUSTER, Juan, “Turismo”, p. 822.

52 FUSTER, Juan, "Estudio", Estudios Turísticos, 34, 1972, pp. 105-114, demostró las carencias de servicios públicos elementales como traídas de agua, redes de alcantarillado, recogida de basuras, etc.. GAVIRIA, Mario: España..., p. 315 y ss., constató en el caso de Fuerteventura la "pobreza administrativa" local y su incapacidad para gestionar el crecimiento turístico.

53 INSTITUTO NACIONAL DE ESTADÍSTICA (1965), Encuesta sobre el turismo..., 1964, Madrid; Ballester Ros (1965), pp. 60-79; García y Jiménez GARCÍA, Eduardo y JIMÉNEZ, Vicente: “Encuesta de turismo receptivo 1970", Revista de Estadísticas Españolas, 53, 1971, pp. 61-89.

54 ALCAIDE, Ángel (1968), p. 43. 
cargo, Sánchez Bella, y al III Plan de Desarrollo (1972-1975). El conocimiento económico del turismo, deficiente, fue mejorando en los primeros 70; a ello colaboró el impulso dado al Instituto de Estudios Turísticos en la reorganización del Ministerio de Información y Turismo de marzo de 1970. Por otra parte, la ordenación de las condiciones mínimas de los alojamientos turísticos, de $1970^{55}$, fue una respuesta dada a la calidad y cantidad de los equipamientos privados y colectivos. Estaba incardinada en la preocupación medioambiental que asomó en la época, coincidiendo con el debate internacional sobre la calidad de vida y la degradación de los ecosistemas. Esta inquietud se plasmó en el programa de la UNESCO Hombre y Biosfera (1971) y en la I Conferencia convocada por las Naciones Unidas sobre el Medio Humano, realizada en 1972 en Estocolmo; a ese mismo año corresponden el Programa de las Naciones Unidas para el Medio Ambiente y el Convenio de Paris para la Protección del Patrimonio Mundial, Cultural y Natural de la UNESCO. Ese clima llevó a organizar en Madrid, en noviembre de 1972, el Congreso de Ecología y Turismo del Mediterráneo Occidental. ${ }^{56}$

Esta preocupación medioambiental, por un lado, y el problema del control exterior de la demanda turística, que repercutía en el relativamente bajo ingreso por turista extranjero, se trasladaron al III Plan de Desarrollo Económico y Social, años 19721975. Éste, ante la excesiva concentración del turismo en el espacio, en el tiempo y en la motivación, apostaba por diversificar la oferta, aumentar su calidad y, con ella, la capacidad adquisitiva de los turistas extranjeros. Esto significaba erosionar el oligopolio ejercido por los tour operadores europeos en los destinos más masificados; sugería para ello estrategias destinadas a captar a los turistas directamente en los mercados emisores de Europa ${ }^{57}$. Esta cuestión llevó al debate sobre si dicha intermediación turística exterior había de efectuarla una agencia pública o agencias privadas en los servicios turísticos españoles en el extranjero, debate que no era nuevo. Además, la desestacionalización podría facilitar, presumiblemente, un desarrollo turístico regional más equilibrado. Detrás de este reconocimiento se encontraban la inquietud por el negativo impacto medioambiental del turismo de sol y playa y por la calidad de la demanda. Para hacer frente a la competencia no bastaban, se decía, los recursos naturales brutos (paisaje, clima, etc.); había que proceder a la "realización de inversiones que garanticen una oferta turística de suficiente calidad".

Las directrices del III Plan de Desarrollo, el igual que las del I y II Plan, daban prioridad al turismo extranjero. Insistían en el aumento de la cantidad, aunque ahora se ponía más énfasis en la calidad ("una clientela más seleccionada que produzca un mayor ingreso medio por visitante") y en la mayor diversificación "espacial y temporal". Se hablaba de mejorar la "infraestructura de servicios comunitarios, comunicaciones y transportes y complementariedad del equipo turístico", de nuevas zonas y nuevos turismos, de estímulo al turismo interior y al "turismo popular" para acrecentar la ocupación de los alojamientos turísticos. Se prometía, al tiempo, proseguir "la ordenación y aprovechamiento del suelo a fin de evitar la especulación,

55 Decreto de 19-12-1970.

56 Sus ponencias están en Estudios Turísticos, 36, 1972.

57 III Plan de Desarrollo Económico y Social, años 1972-1975, Madrid, 1971, pp. 76-77. 
asegurar la defensa del paisaje y conseguir unas construcciones turísticas adecuadas al ambiente local." Para ejecutar muchas de esas actuaciones era obligada una mayor coordinación de los ministerios de Obras Públicas y de Turismo, reconocidamente deficiente. ${ }^{58}$

En esas se estaba cuando llegó la recesión al sector, en 1974-1975, provocada por la crisis del petróleo. Ante ella se respondió con "buenas intenciones"59, que llevaron a la aprobación en agosto de 1974 de un paquete de medidas relativas al sector turístico, siendo ministro Pío Cabanillas. Fue anunciado como una nueva política turística, más beligerante en cuanto a la ordenación de la oferta, a la modernización de la planta hotelera, a la proyección exterior de las agencias y empresas turísticas españolas, y restrictiva con la inversión extranjera. Pero las medidas no evitaron la recesión, la primera que afectó seriamente a los ingresos por turismo y a los turistas extranjeros en la segunda mitad del siglo XX. La recesión, prolongada hasta 1977 en el número de turistas, fue importante pero no quebró la fortaleza adquirida por el turismo receptivo e interior en España. El turismo había venido a finales de la década de 1940 para quedarse.

\section{Balance final}

España inició el siglo XX como una nación de segundo orden en cuanto al turismo internacional, aunque con una voluntad manifiesta, desde la iniciativa privada y pública, de desarrollar la "industria del turismo" o "industria de los forasteros", de la que se habla en los medios escritos desde 1903-1904. Finalizada la centuria se había consolidado como una potencia turística mundial. Ese protagonismo en el mercado turístico mundial se alcanzó durante la década de 1960, bajo la dictadura de Franco. España se convirtió en el destino preferido por el turismo de masas de sol y playa con origen en los países europeos industrializados (Francia, Gran Bretaña, Alemania). En esos años, el turismo exterior se transformó en una riada veraniega, en una especie de invasión pacífica que desbordaba las playas de varias provincias mediterráneas y de las Islas Baleares y Canarias, con unas cifras que casi igualaron al total de la población española a principios de los años setenta. Un fenómeno de esta naturaleza tenía que producir, indudablemente, un notable impacto económico, social y político. El turismo colaboró a modelar la dinámica socio-demográfica de las provincias españolas, a modernizar sus costumbres, a europeizar el país, a hacer, en fin, su vida más moderna. Cuando murió Franco en 1975, el turismo era uno de los elementos constitutivos de la vida española, como deseaba en 1909 el Conde de Bailén.

Ahora bien, en la España franquista el fenómeno turístico no se limitó al turismo receptivo y sus efectos económicos no se ciñeron a las divisas que convirtieron los ingresos por turismo en la principal partida compensadora de los déficit de la balanza de pagos, ni estos aportes se limitaron a la etapa 1960-1975. El turismo generó,

58 III Plan de Desarrollo..., pp. 162 y 78.

59 Figuerola, Manuel: "Política de turismo", en Luis GÁMIR: Política económica de España, Madrid, 1980, p. 906. 
desde los primeros años 1950, una importante industria que impactó sobre el empleo y el Producto Interior Bruto, a través del efecto multiplicador del gasto turístico. Por otra parte, la compensación del desequilibrio de la balanza exterior de la economía española fue ya significativo desde finales de la década de 1940. El turismo, así, fue clave en la supervivencia financiera del régimen de Franco (como vemos en 1947 y en 1959) y en el desarrollo económico y social del período. Es imposible entender el modelo de desarrollo español de esta época sin considerar el papel de las variables turísticas, al igual que sucede en las décadas posteriores y comprobamos en lo que llevamos del siglo XXI. Hasta aquí la bendición.

En el saldo final del turismo hay, no obstante, luces y sombras, ganancias y costes sociales que obligan a huir del triunfalismo y aconsejan una valoración ponderada de sus presumibles beneficios netos. El turismo tuvo en la España franquista su dosis de plaga. En primer lugar, la evolución turística acentuó la orientación terciaria de la economía española, cuando apenas había completado su industrialización moderna. En segundo lugar, dado su alto componente exterior, tuvo una excesiva dependencia del consumo de los no residentes. Este turismo exterior, canalizado cada vez más a través de vuelos chárter, fue gestionado por potentes turoperadores extranjeros, con capacidad de imponer precios, de modo que la demanda y sus intermediarios llegaron a controlar buena parte de la oferta, originando una especie de dependencia colonial en las provincias en que la presencia de aquéllos fue mayor. Allí donde existían enclaves o complejos turísticos controlados o participados por inversores extranjeros, esta dependencia fue mayor. En algunas de esas provincias ese modelo turístico originó una visible colonización inmobiliaria el territorio.

El "boom del turismo" estimuló una intensa fiebre constructora en el litoral afectado, ya desde el tránsito de la década de los cincuenta a los setenta, altamente especulativa, con nuevas formas de alojamiento, los bloques de apartamentos, fuera de la hostelería reglada. Esos desarrollos urbanísticos han consumido paisajes naturales de forma abusiva y excesiva, convirtiendo la destrucción paisajística en un efecto permanente, de difícil o imposible reversibilidad, a la vez que han conformado urbanizaciones que trasladan altos costes de gestión para los ayuntamientos. Esta cultura inmobiliaria especulativa, depredadora, ha quedado enquistada en la sociedad española, especialmente en las provincias más turísticas. Alguien tan poco sospechoso de ser un crítico del turismo como Jorge Vila Fradera ha escrito a este respecto que, un "elemento fuertemente impulsor del desbocado desarrollismo durante varios periodos históricos de nuestro turismo ha sido el fenómeno de la especulación del suelo (...) produciéndose el deterioro del sector [turístico] en determinadas áreas por saturación y exceso de oferta. Las constructoras siguen siendo dependientes de su obsesión por seguir edificando... que luego se verá" ${ }^{60}$. Este modelo que combina turismo de masas y construcción, visible en Canarias, la comunidad de Valencia, Andalucía o Baleares, introduce elementos tensión y fragilidad sobre el resto de la estructura productiva de estos territorios, que afectan asimismo al empleo y a su calidad.

Estos desarrollos turísticos repercuten asimismo en la calidad del paisaje natural y de los pueblos y paisajes urbanos históricos, dando lugar a esquemas difícilmente

60 VILA, Jorge, La gran aventura del turismo en España, 1997, pp. 34-35. 
sostenibles desde el punto de vista medioambiental. Entre sus externalidades negativas se cifran la degradación de la biodiversidad, la deforestación, las pérdidas de cobertura vegetal, la erosión e incluso desertificación, la salinización de los suelos o el incremento de la contaminación acústica, edáfica e hídrica, tanto superficial como profunda, terrestre y marítima. ${ }^{61}$ Otras consecuencias son la desaparición de las arquitecturas históricas, tradicionales, y el cambio sociológico, en detrimento de las culturas locales, que mutan en fórmulas simbióticas, adaptadas a veces artificialmente a las expectativas de los turistas. Los testimonios literarios y gráficos de los años sesenta y primeros setenta son muy elocuentes al respecto. Algunos se han traído a este trabajo.

61 Véase, para el caso de Valencia, ALMENAR, Ricardo, BONO, Emèrit y GARCÍA, Ernest (dirs.), La sostenibilidad del desarrollo: el caso valenciano, UVA/Bancaixa, 2000. 